\title{
The Role of Parathyroid Hormone- Related Protein in the Regulation of Osteoclastogenesis by Cementoblasts
}

Fernanda Boabaid, ${ }^{* \dagger}$ Janice E. Berry, ${ }^{*}$ Amy J. Koh, ${ }^{*}$ Martha J. Somerman, ${ }^{\ddagger}$ and Laurie K. McCauley*§

Background: Parathyroid hormone-related protein (PTHrP) promotes osteoclastogenesis by inhibiting expression of osteoprotegerin (OPG), a decoy receptor for the receptor activator of nuclear factor kappa B (RANK), and by enhancing production of RANK ligand (RANKL) by osteoblasts. However, little is known regarding the role of PTHrP in regulating cementoblast-mediated osteoclastogenesis.

Methods: This study determined the impact of PTHrP on osteoclastogenesis using: 1) OCCM-30 (immortalized murine cementoblasts), 2) RAW 264.7 cells (murine myeloid cells), or 3) OCCM-30 plus RAW 264.7 cells. Cells were treated with PTHrP (1-34), RANKL, or PTHrP and RANKL combined. Enzyme-linked immunosorbent assays (ELISAs) for OPG and RANKL were performed on media and cell lysates, and tartrate-resistant acid phosphatase (TRAP) and mRNA detection for the osteoclast associated receptor (OSCAR) were performed.

Results: The highest numbers of TRAP-positive cells and cells expressing OSCAR were found in the RAW cell group treated with either RANKL alone or RANKL and PTHrP. TRAP-positive cells were fewer when OCCM cells were co-cultured with RAW, but the greatest numbers were still with both PTHrP and RANKL. OPG levels were highest from OCCM cells and PTHrP decreased these levels. In contrast, RANKL levels were low in OCCM cell lysates and PTHrP increased RANKL. In vivo studies also revealed high osteoclastic activity surrounding developing teeth in mice administered PTH.

Conclusions: These results demonstrate that PTHrP influences the balance of OPG and RANKL production by cementoblasts, and further indicate that this effect, in the context of surrounding cells, might have a significant impact on osteoclastogenesis, root resorption, and tooth eruption. J Periodontol 2004;75:1247-1254.

\section{KEY WORDS}

Cementoblasts; ligand, NF-kappa B; osteoblasts; osteoclasts; osteoprotegerin; proteins, parathyroid hormone related; receptor activator, NF-kappa B; tooth eruption; tooth root.

* Department of Periodontics/Prevention/Geriatrics, School of Dentistry, University of Michigan, Ann Arbor, MI.

$\dagger$ Department of Morphology, School of Medicine, Federal University of São Paulo, São Paulo, SP, Brazil.

† Department of Periodontics, School of Dentistry, University of Washington, Seattle, WA.

$\S$ Department of Pathology, Medical School, University of Michigan.
A series of cellular and molecular events operate to promote tooth formation and subsequently eruption into the oral cavity. Several systemic and local factors are considered important for inducing differentiation and proliferation of various types of cells, promoting development of teeth and surrounding periodontal tissues, and creating a pathway for tooth eruption. ${ }^{1}$

Parathyroid hormone-related protein (PTHrP) is a local factor which has paracrine and/or autocrine functions, including controlling tissue and organ development, differentiation, proliferation, and cell survival via its interaction with the type I PTH/ PTHrP receptor (PTH-1R). 2,3

The process of tooth eruption provides a valuable physiological model to analyze bone resorption/remodeling and its use has revealed that PTHrP is essential for promoting osteoclastogenesis and bone resorption during tooth eruption. ${ }^{4-6}$ Mice or humans with loss of PTHrP function have tooth impaction, ${ }^{7}$ failure of eruption, ${ }^{8}$ and fusion of cementum with surrounding alveolar bone. ${ }^{6}$ Replacement of PTHrP restores these defects in mice. ${ }^{4}$ During early events of tooth development, PTHrP is produced by cells of epithelial origin, known as the stellate reticulum and by Hertwig's epithelial cells. Cells of mesenchymal origin in the area, follicle cells, osteoblasts, and cementoblasts, produce PTHrP but at much lower levels. ${ }^{9}$ PTH and PTHrP share the same receptor, the G protein-coupled PTH-1R. ${ }^{2}$ These tooth-associated cell types of mesenchymal origin 
also express the PTH-1R. ${ }^{5,10-12}$ The actions of PTHrP on cells within the local environment, including follicle cells and osteoblasts, result in the recruitment of precursors of the monocyte-macrophage lineage to the site of bone resorption, fusion of these cells into multinucleated osteoclasts, consequent alveolar bone resorption, and creation of the tooth eruption pathway. ${ }^{13,14}$

Osteoclastogenesis and bone resorption are regulated by production of the TNF receptor-ligand family members, osteoprotegerin (OPG) and receptor activator of nuclear factor kappa B (NF- $\kappa \mathrm{B}$ ) ligand (RANKL) by osteoblast/stromal cells. ${ }^{15}$ RANKL is both a membraneassociated cytokine and a bone microenvironmentassociated soluble factor that binds to the receptor activator of NF- $\mathrm{KB}$ (RANK) on osteoclast precursor cells to promote osteoclastogenesis. OPG, a secreted glycoprotein, acts as a decoy receptor by binding to RANKL, and inhibiting osteoclastogenesis. ${ }^{16-18}$ As an osteotropic factor, PTHrP promotes osteoclastogenesis by increasing levels of RANKL and decreasing OPG in osteoblast/ stromal cells. ${ }^{19-21}$

In the tooth microenvironment, OPG is expressed by follicle cells and is downregulated by PTHrP. ${ }^{1,13}$ Expression of OPG/RANKL mRNA has been detected in human periodontal ligament cells (PDL) in culture ${ }^{22}$ and localized in vivo by immunohistochemistry in ameloblasts, odontoblasts, and dental pulp cells. ${ }^{23}$ Interestingly, root resorption is an uncommon event that is considered pathologic versus the physiological bone resorption that normally occurs as part of bone remodeling. The actions of PTHrP on cementoblasts and their role in osteoclastogenesis or odontoclastogenesis is poorly understood. The purpose of this study was to determine the role of PTHrP in regulating the expression of OPG/ RANKL by cementoblasts and subsequently the promotion of osteoclastogenesis. A better understanding of the role of PTHrP-cementoblast interactions during tooth eruption and periodontal development will contribute to the design of clinical strategies to address dysregulated tooth eruption, as well as periodontal diseases.

\section{MATERIALS AND METHODS}

\section{Cell Culture and Treatments}

Two cell lines were used for these experiments. OCCM30 cells are an immortalized murine cementoblast cell line previously described. ${ }^{24}$ The murine myeloid cell line RAW 264.7 is an osteoclast mononuclear precursor cell line. Cells were plated in triplicate as follows: OCCM alone, RAW 264.7 alone, or coculture of OCCM + RAW 264.7, in $60 \mathrm{~mm}$ dishes or 12-well plates at densities of 25,000 cells $/ \mathrm{cm}^{2}$ for OCCM and 5,000 cells $/ \mathrm{cm}^{2}$ for RAW 264.7. After plating (day 0) cells were maintained in Dulbecco's modified Eagle medium (DMEM) plus $10 \%$ fetal bovine serum (FBS) containing $100 \mathrm{U} / \mathrm{ml}$ of penicillin and $100 \mu \mathrm{g} / \mathrm{ml}$ streptomycin" in a humidified atmosphere of $5 \% \mathrm{CO}_{2}$ at $37^{\circ} \mathrm{C}$. On day 2, supernatants were collected and all groups were switched to DMEM $5 \%$ FBS containing penicillin/streptomycin and treated as follows: 1) no treatment (control), 2) RANKL (0.2 $\mu \mathrm{g} / \mathrm{ml})$, "l 3) PTHrP 1-34 (0.1 $\mu \mathrm{M}),{ }^{\#}$ and 4) RANKL (0.2 $\mu \mathrm{g} / \mathrm{ml})$ plus PTHrP 1-34 $(0.1 \mu \mathrm{M})$. Treatments were replaced on day 4 after the collection of supernatants.

\section{In Vivo Experiments}

Pregnant mice at 16 days of gestation (day 0 , vaginal plug date) were given daily subcutaneous injections of either recombinant human PTH 1-34 $(10 \mu \mathrm{g} / \text { day })^{\#}$ or vehicle $(0.9 \%$ sodium chloride) until delivery on day 19 according to a UCUCCA-approved protocol. PTH 1-34 and PTHrP 1-34 have similar osteoclast-inducing biologic activity ${ }^{2}$ and can be used interchangeably in this model of osteoclast induction. Maxillary first molar segments were removed from offspring mice 3 days after birth (day 22 of development). Specimens were fixed in 10\% neutral buffered formalin for 24 hours, decalcified in 10\% EDTA for 5 days at room temperature, dehydrated in ascending series of ethanol, embedded in paraffin, and serial sagittal sections generated at $5 \mu \mathrm{m}$ thickness.

\section{TRAP Staining}

Tartrate-resistant acid phosphatase (TRAP) stain was performed on tissue sections from in vivo studies, following instructions from a commercial leukocyte acid phosphatase assay system. * * Briefly, slides were deparaffinized in xylene; hydrated in serial ethanol; and incubated in a solution containing diazotized fast garnet, napthol ASBI phosphate, acetate, and tartrate solution for 1 hour at $37^{\circ} \mathrm{C}$, while protected from light. Sections were rinsed in $\mathrm{dH}_{2} \mathrm{O}$ and counterstained with hematoxylin. Histomorphometric analysis was performed using a computerassisted program ${ }^{\dagger \dagger}$ and analytic software ${ }^{\ddagger \dagger}$ with a light microscope. The following measurements were taken: total linear perimeter of alveolar bone surface surrounding the tooth germ and number of TRAP-positive osteoclasts per mm of osseous perimeter. Results were expressed as mean \pm SEM of 14 samples for each group.

For in vitro studies, cells were plated in 12-well plates and treated as described. After 5 days, cells were fixed in citrate buffered acetone/formaldehyde for 1 minute. Staining for TRAP was performed following instructions from a commercial leukocyte acid phosphatase kit** as described above. TRAP-positive osteoclasts were quantified by counting the number of multinucleated red-stained cells. Results were expressed as number of TRAP-positive cells per well.

\footnotetext{
II Invitrogen, Grand Island, NY.

I PeproTech, Rocky Hill, NJ.

\# Bachem, Torrance, CA.

* * Sigma, St. Louis, MO.

$\dagger \dagger$ Image-Pro Plus 4.1, Media Cybernetics, Silver Spring, MD.

牛 SPOT RT Diagnostic Inst. 3.0, Sterling Heights, MI.
} 


\section{Enzyme-Linked Immunosorbent Assay (ELISA) for OPG and RANKL}

Cells were seeded in 12 -well plates and treated as described above. Media were collected at days 2, 4, and 5 and frozen at $-20^{\circ} \mathrm{C}$. At day 5 , cells were removed from the plates by scraping in $1 \mathrm{ml}$ lysis buffer $(150 \mathrm{mM} \mathrm{NaCl}$, $10 \mathrm{mM}$ phosphate buffer $\mathrm{pH} 7,1 \% \mathrm{NP} 40,0.1 \%$ SDS, $1 \%$ sodium deoxycholate), vortexed and centrifuged. Supernatants were removed and transferred to new tubes, and total protein concentration was measured according to instructions from a Bradford-based protein assay. $\S \S$

An ELISA to detect OPG and RANKL was performed from collected media on days 2, 4, 5 and from cell lysate processed on day 5. For OPG levels, collected supernatant and lysate were diluted 1:10. ELISAs were performed following the instructions from assay systems specifically designed to measure these proteins ${ }^{\|1\|}$ and results were normalized to protein levels.

\section{Real-Time PCR}

Cells were plated in $60 \mathrm{~mm}$ dishes and treated as described above. Total RNA was harvested from OCCM alone, RAW alone, or OCCM + RAW cocultures for quantitative analysis of OSCAR gene expression by real-time polymerase chain reaction (PCR). 1 \% Briefly, RNA was isolated from $60 \mathrm{~mm}$ dishes using guanidinium isothiocyanate $^{25}$ and treated with the DNA-free DNAase reagent system ${ }^{\# \#}$ to eliminate genomic DNA. One microgram of total RNA was reverse transcribed to cDNA using TaqMan reverse transcriptase reagents*** following the manufacturer's protocol using a thermal cycler. ${ }^{\dagger \dagger \dagger}$

Real-time PCR amplification reactions for GAPDH for normalization were performed in $25 \mu \mathrm{l}$ containing $1 \mu \mathrm{l}$ cDNA, $12.5 \mu \mathrm{l} 2 \times$ TaqMan universal PCR master mix, $100 \mathrm{nM}$ probe, and $100 \mathrm{nM}$ primers. OSCAR reactions were performed in $20 \mu \mathrm{l}$, containing $9 \mu \mathrm{l}$ cDNA, $10 \mu \mathrm{l} 2 \times$ TaqMan universal PCR master mix, $100 \mathrm{nM}$ probe, and $100 \mathrm{nM}$ primers. The sequences of primers and probes used were: OSCAR sense GGGCATGAGTTTTGCACTG TAC-18', antisense GGGCTGCACAGAGTCAATATACTG18', FAM probe TTGCCACGCCTACGCG-5'. Amplification conditions were 2 minutes at $50^{\circ} \mathrm{C}$ and 10 minutes at $95^{\circ} \mathrm{C}$, then 40 cycles of denaturation at $95^{\circ} \mathrm{C}$ for $15 \mathrm{sec}-$ onds, and annealing at $60^{\circ} \mathrm{C}$ for 1 minute. To control for variability in amplification due to differences in starting cDNA concentrations, GAPDH primers and probe from a commercial source ${ }^{* * *}$ were used as an internal standard. Threshold cycle $C_{t}$, which correlates inversely with the target mRNA levels, was measured as the cycle number at which the reporter fluorescent emission increases above a threshold level. The relative expression of target mRNA was calculated from $C_{t}$ values normalized to GAPDH.

\section{Statistical Analysis}

Assays were performed two or three times with similar results. All data were examined using analysis of

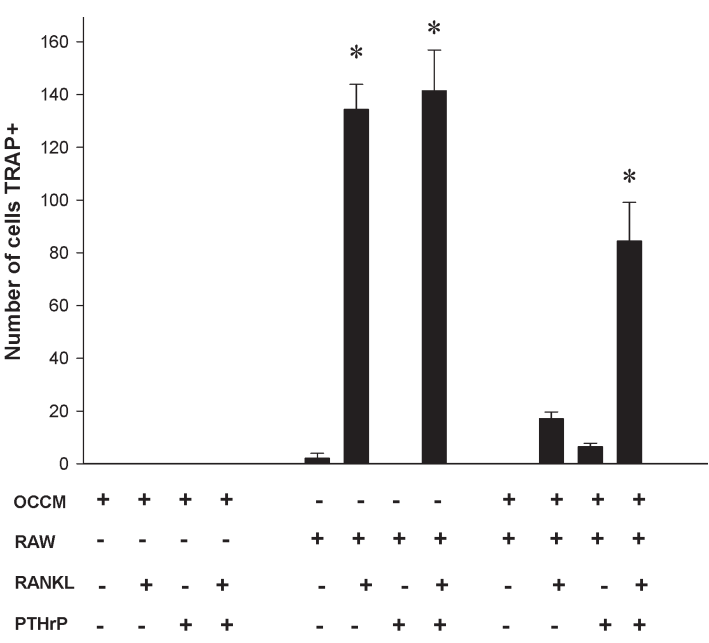

Figure I.

TRAP staining to detect multinucleated osteoclasts (red-stained multinucleated cells) after 5 days of treatment with $R A N K L(0.2 \mu \mathrm{g} / \mathrm{ml})$, PTHrP (I-34) (0.I $\mu \mathrm{M})$, or a combination of RANKL and PTHrP. $* P<0.001$ versus respective group control without treatment. Data are presented as mean \pm SEM of triplicate samples.

variance with a Bonferroni multiple comparisons posttest using a biostatistical program ${ }^{\neq} \neq$and significance set at $P<0.05$.

\section{RESULTS}

\section{TRAP Staining}

Cell cultures at day 5 were evaluated for TRAP-positive cells. OCCM cells alone did not stain for TRAP, regardless of treatment (Fig. 1). RAW cells treated with RANKL alone or in combination with PTHrP had the highest number of TRAP-positive multinucleated osteoclasts (134.3 \pm 5.5 and $141.3 \pm 9.0$ per well, respectively), while PTHrP alone was not able to induce osteoclastogenesis of RAW cells.

Untreated OCCM/RAW co-cultures did not have any TRAP-positive multinucleated osteoclasts. When RANKL was added to the coculture there was an increase in TRAP-positive multinucleated osteoclasts $(17 \pm 1.5)$ but much less than RAW cells alone treated with RANKL. PTHrP treatment of cocultures resulted in few TRAPpositive mononucleated osteoclasts; however, when cells were treated with PTHrP in combination with RANKL there was a significant increase in numbers of TRAPpositive multinucleated osteoclasts $(84.3 \pm 8.6)$, but still not as great as the number of positive cells in the RAW cells cultured with RANKL.

$\S \S$ DC Protein assay, Bio-Rad, Hercules, CA.

\|I Quantikine mouse OPG and RANKL kit assay systems, R \& D Systems Minneapolis, $M N$.

ๆ Foster City, CA.

\#\# Ambion Inc., Austin, TX.

*** Applied Biosystems.

$\dagger \dagger \dagger$ Peltier PTC-200, MJ Research, Inc., Watertown, MA.

沛 Instat 2.1 biostatistical program, GraphPad Software, San Diego, CA. 
In vivo results support the in vitro findings. In a complex tissue model during development where PTH was administered for 3 days, an increase in the number of TRAP-positive osteoclasts was found surrounding the developing teeth of PTH-treated animals as compared to vehicle-treated mice (Fig. 2). This increase in TRAPpositive multinucleated cells was evident along the perimeter of alveolar bone surrounding the developing molar.

\section{ELISA}

OPG and RANKL levels were analyzed by ELISA in media collected on days 2,4 , and 5 , and in cell lysates from day 5. OPG was produced in high levels in untreated OCCM cells with levels increasing from day 2 to day 5 (Fig. 3), and all treatments significantly reduced levels. Expression of OPG by OCCM cells treated with RANKL was much lower in media on day 4 (4-fold lower) and day 5 (8-fold lower) versus untreated OCCM on the corresponding day (Figs. 3B, 3C). PTHrP added to OCCM decreased levels of OPG 5 -fold on day 4 and 9 -fold on day 5. The combination of RANKL + PTHrP treatment on OCCM cells resulted in a decrease in OPG levels, 11 fold on day 4 (Fig. 3B) and 25-fold on day 5 (Fig. 3C) when compared with untreated OCCM. OPG was not detected in media from RAW cells alone or from RAW cells treated with RANKL, PTHrP, or RANKL and PTHrP (data not shown). The untreated co-culture of OCCM and RAW cells exhibited significantly lower levels of OPG in media when compared with OCCM alone. On day 4, OPG levels in co-culture of OCCM and RAW were 4 -fold lower than OCCM alone and on day 5 were 18-fold lower. Levels of OPG in media with the addition of RANKL or PTHrP were not significantly different compared with the untreated group but the combination of

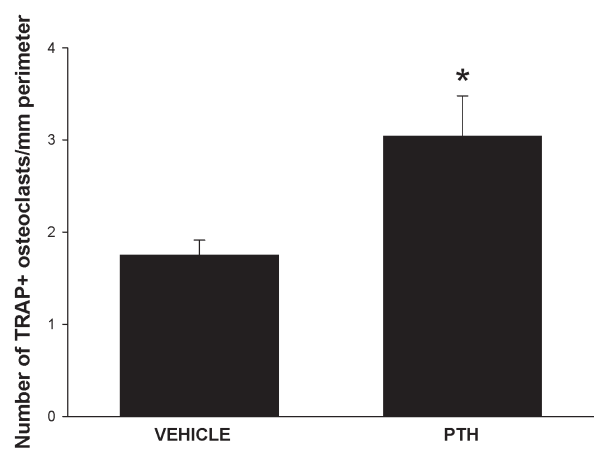

Figure 2.

TRAP staining was performed on sections of maxillary first molars of neonatal mice whose mothers were injected with PTH I-34 for 3 days prior to birth ( $10 \mu \mathrm{g} /$ day). PTH treated animals had increased numbers of TRAP-positive osteoclasts on the osseous perimeter surrounding the developing tooth germ. Numbers of TRAP-positive osteoclasts per $\mathrm{mm}$ osseous perimeter are plotted with $n=14$ mice/group. Data are presented as mean \pm SEM. *P $<0.05$ versus vehicle treatment.
A

Day 2

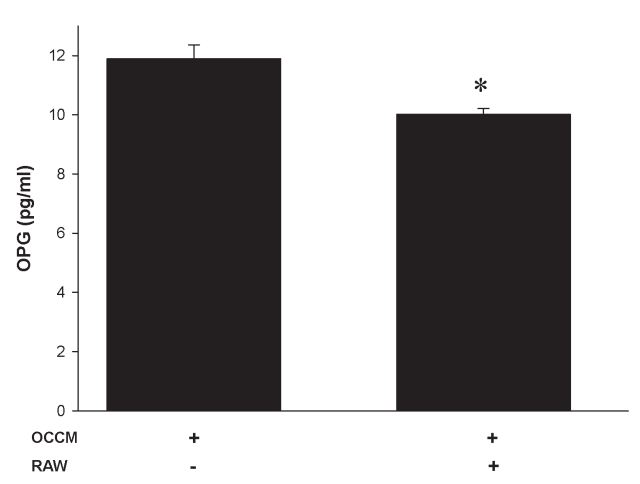

B

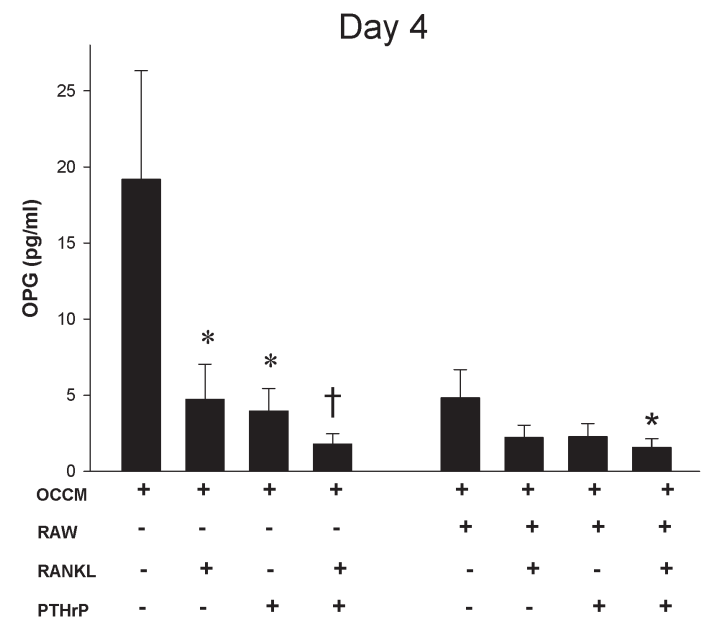

C

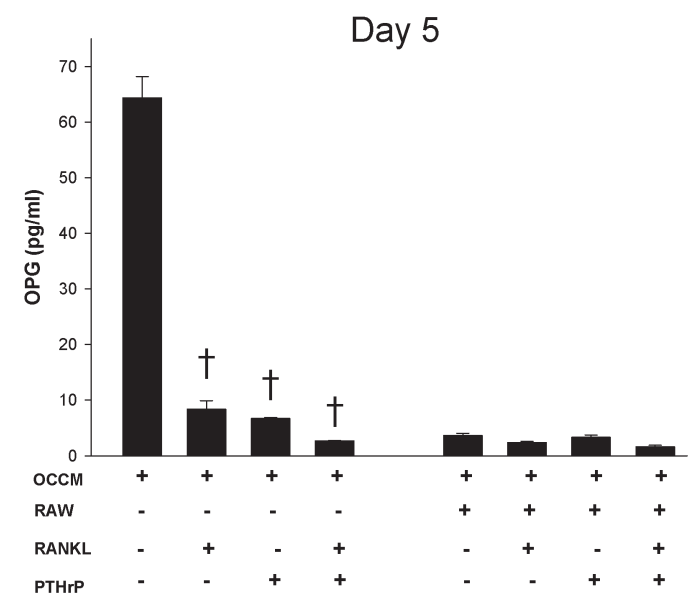

Figure 3.

OPG levels were measured by ELISA in media collected on day 2, prior to addition of treatments $(\mathbf{A})$; day 4, prior to addition of treatments $(\mathbf{B})$; and day 5 (C). OCCM, RAW, and OCCM + RAW cells were treated with RANKL $(0.2 \mu \mathrm{g} / \mathrm{ml})$, PTHrP I-34 (0.1 $\mu \mathrm{M})$, or RANKL + PTHrP on days 2 and 4.

OPG levels were not detected in media from RAW cells under any conditions (data not shown). $* P<0.05$, $\mathrm{\dagger} P<0.00$ I versus group control without treatment. Data are expressed as mean \pm SEM of triplicate cultures. 
RANKL and PTHrP significantly lowered OPG levels in day 4 co-cultures.

In contrast to OPG, levels of RANKL in media from untreated OCCM cells cultured alone displayed a trend toward decreasing over time from day 2 to day 5 (Fig. 4). RANKL levels were 5-fold higher at day 4 in media from OCCM cells treated with RANKL versus untreated (Fig. 4B), but this effect was not observed on day 5 (Fig. 4C). The addition of PTHrP did not significantly increase RANKL in media from OCCM cells alone by day 5 (Fig. 4C); however, the combination of RANKL and PTHrP increased RANKL levels (5-fold) on day 5 in these cell cultures.

Media from RAW cells alone contained measurable RANKL on day 2 (2.8 \pm 0.5$)$ (Fig. 4A), and these levels were increased with RANKL alone or the combination of RANKL and PTHrP at day 5 (4-fold) compared to untreated RAW cells (Fig. 4C).

In co-culture, RANKL levels in secreted media were low for the untreated group on days 4 and 5, similar to untreated OCCM and RAW cells alone (Figs. 4B and $4 \mathrm{C}$ ). RANKL treatment promoted an extremely significant 38-fold increase in RANKL levels on day 4 (Fig. 4B), but this effect was diminished on day 5 (Fig. 4C) when compared with control. Cells in co-culture treated with PTHrP showed mild but not significant increases in RANKL on day 4 and day 5 when compared to untreated co-cultures, but the combination of RANKL with PTHrP promoted a significant increase in these levels on day 4 (22-fold) with still significant but lower levels on day 5 (5-fold) (Figs. 4B and 4C).

Analysis of cell lysates at day 5 revealed that OCCM cells contained high levels of OPG, which was unaffected by treatment with RANKL, but was highly inhibited by treatment with PTHrP or RANKL plus PTHrP (5-fold reduction) (Fig. 5A). In co-cultures (OCCM +RAW), the level of OPG was significantly lower when compared to OCCM alone and the effects of treatments were insignificant. OPG was not detected in RAW cell lysates under any condition (data not shown).

RANKL levels in untreated OCCM cell lysates were low and were unaffected by addition of RANKL (Fig. 5B). PTHrP or PTHrP with RANKL increased this level 9-fold and 12-fold, respectively. RANKL levels were higher in untreated RAW cells than untreated OCCM cells and the addition of RANKL reduced RAW RANKL levels. RAW cell co-cultures with untreated OCCM cells promoted an increase of 12-fold in levels of RANKL in cell lysate when compared to OCCM cells alone; however, all treatments decreased levels of RANKL in cell lysates.

\section{Real-Time PCR for OSCAR Gene Expression}

Analysis of OSCAR gene expression quantification by real-time PCR revealed increased OSCAR gene expression on RAW cells alone treated with RANKL (11-fold) and RANKL combined with PTHrP (6-fold) compared to
Day 2

A

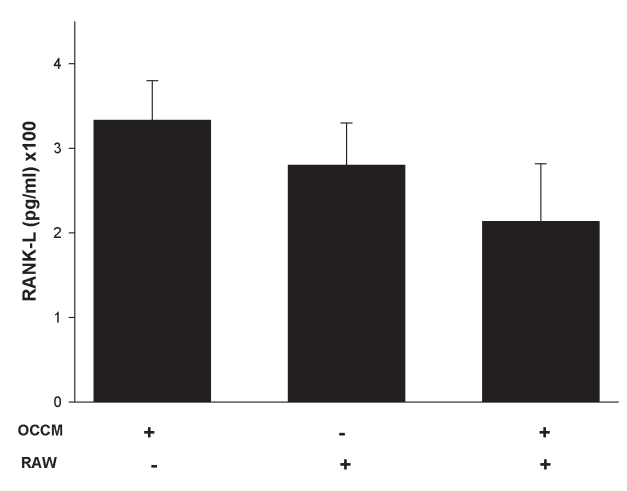

B

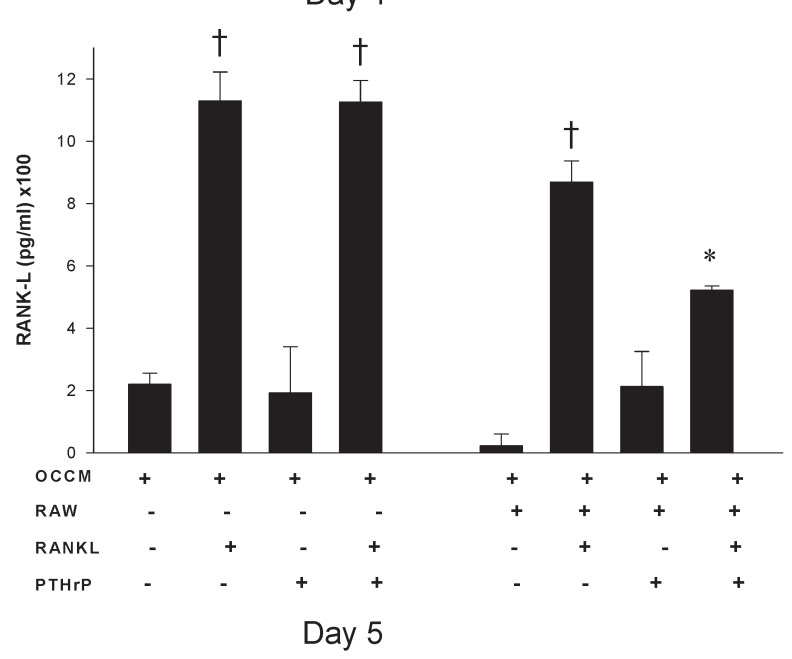

C

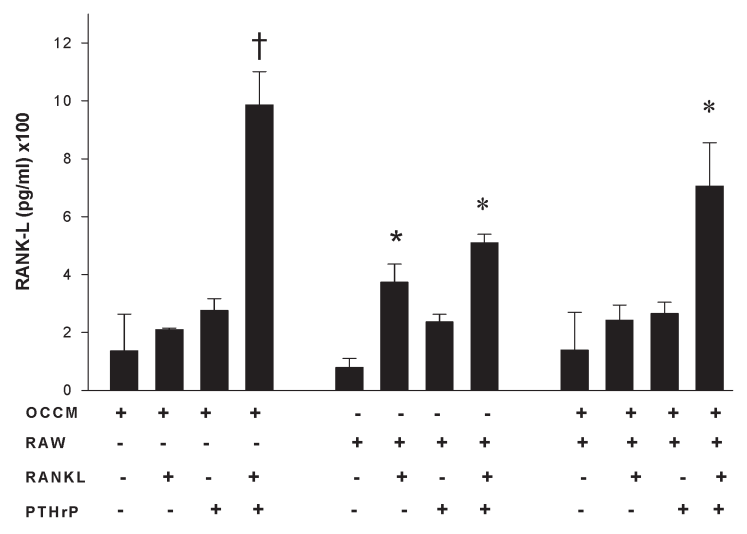

Figure 4.

RANKL levels were measured by ELISA from media collected on day 2, prior to addition of treatments $(\boldsymbol{A})$; day 4, prior to addition of treatments (B); and day 5 (C). OCCM, RAW, and OCCM + RAW cells were treated with RANKL $(0.2 \mu \mathrm{g} / \mathrm{ml})$, PTHrP I-34 (0.I $\mu \mathrm{M})$, or RANKL + PTHrP on days 2 and $4 . * P<0.05,+P<0.00$ I versus respective group control without treatment. Data are expressed as mean \pm SEM for triplicate samples.

untreated RAW cells (Fig. 5C). In co-culture, no significant changes of OSCAR gene expression were observed with any treatments resulting in reduced OSCAR mRNA 
A

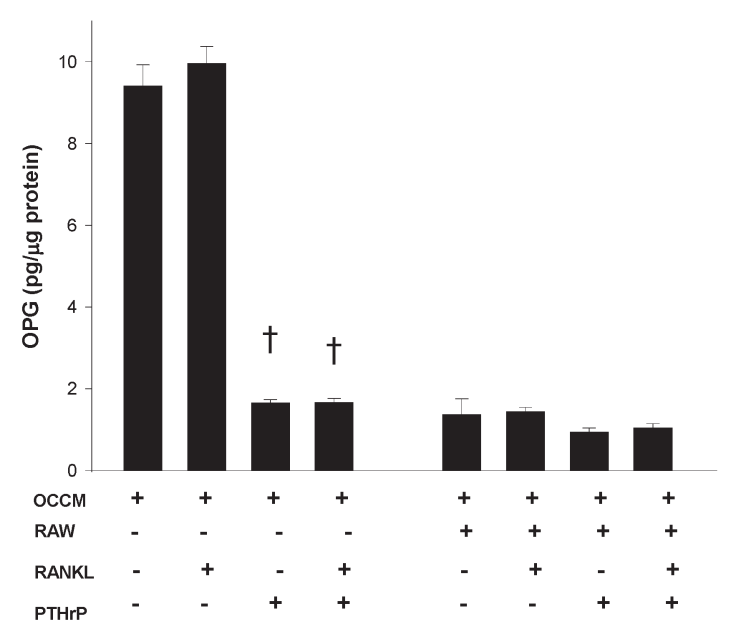

B

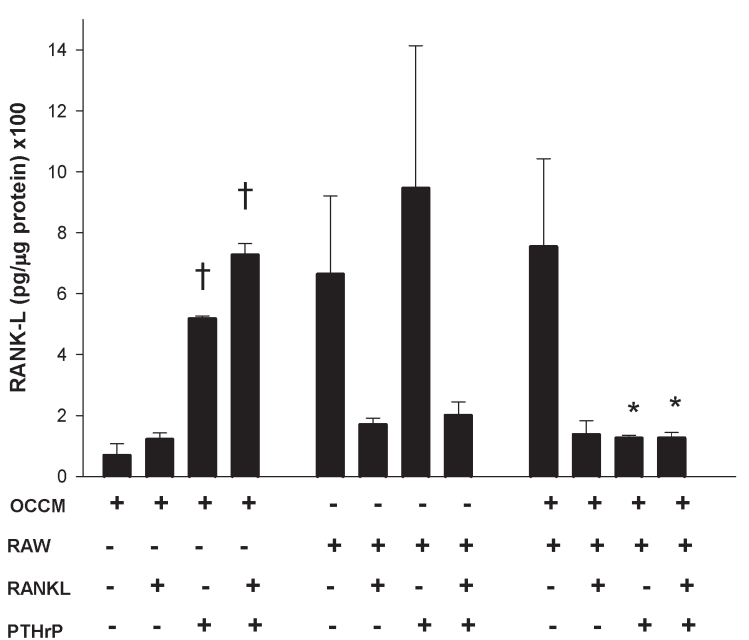

C

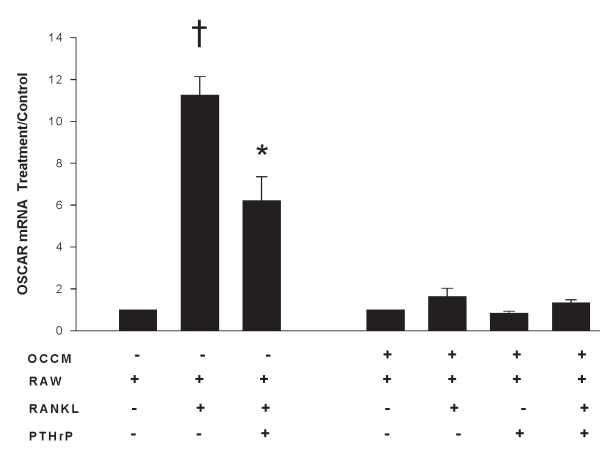

Figure 5.

OPG (A) and RANKL (B) levels were measured by ELISA in cell lysates. OSCAR mRNA was measured by real-time PCR from cells obtained on day 5 (C). OCCM, RAW, and OCCM + RAW cells were treated with RANKL $(0.2 \mu \mathrm{g} / \mathrm{ml})$, PTHrP I-34 $(0.1 \mu \mathrm{M})$, or RANKL + $P T H r P$. $* P<0.05,{ }^{\top} P<0.001$ versus respective group control without treatment. Data are expressed as mean \pm SEM for triplicate samples. levels in treated co-cultures as compared to treated RAW cell cultures alone.

\section{DISCUSSION}

OPG and RANKL are proteins that can be controlled by a variety of factors, resulting in inhibition or promotion of osteoclastogenesis. ${ }^{21}$ The expression of OPG and RANKL and their involvement in osteoclastogenesis during tooth development and eruption, as well as expression in periodontal tissues has been described. 5,22,23,26-29 The present study extends these observations to the identification and regulation of OPG and RANKL in cementoblasts and the ability of PTHrP to alter levels of OPG and RANKL and to affect osteoclastogenesis.

Results from the present study indicate that, similar to osteoblastic cells, PTHrP is capable of regulating osteoclast formation via a balance between expression of OPG and RANKL. Additionally, they demonstrate that cementoblasts synthesize and secrete OPG and further inhibit osteoclast formation in co-culture with osteoclast mononuclear precursor cells, which suggests that cementoblasts may be responsible for maintaining lower levels of osteoclastic activity at the root surface as compared to the adjacent alveolar bone. In this study, PTHrP acted on cementoblasts to decrease levels of OPG and promoted the development of TRAP-positive osteoclasts in co-culture alone and in combination with RANKL. These findings suggest that the protective role of OPG against osteoclastic mediated alveolar bone resorption in periodontal tissues and perhaps root resorption may be dysregulated by PTHrP and/or other factors that regulate the ratio of OPG/RANKL in periodontal tissues, and that cementoblasts may be active participants in this action.

Studies have shown RANKL mRNA and protein expression in the cytoplasm of osteoblasts, osteocytes, osteoclasts, and periodontal ligament fibroblasts, ${ }^{22,30}$ and also in the rough endoplasmic reticulum (RER). ${ }^{31}$ Studies have also shown that expression of RANKL mRNA can be upregulated in response to osteotropic factors such as PTHrP. ${ }^{32,33}$ Cementoblasts are target cells for PTHrP ${ }^{10}$ and our results now show that cementoblasts respond to PTHrP treatment by increasing synthesis of cell-associated RANKL.

The importance of PTHrP in osteoclastogenesis was evident from results of studies with PTHrP knockout mice, where impaction of tooth germs and failure of tooth eruption were found. ${ }^{6,14}$ Replacement of PTHrP promoted differentiation of precursor cells into TRAPpositive osteoclasts, thus restoring bone resorption and subsequently tooth eruption. ${ }^{4}$ Our results with cementoblasts in co-culture with mononuclear precursor cells indicate that root surface cells respond to PTHrP in a similar fashion as adjacent osteoblasts. Added PTHrP promoted the differentiation of TRAP-positive multinucleated osteoclasts by inhibiting OPG and increasing RANKL levels. Additional soluble RANKL in this system 
was also enough to promote TRAP-positive cells to a similar extent as that induced by PTHrP. In contrast to our results, Fuller et al. reported no additive effect with the combination of PTHrP and RANKL on osteoblasts, ${ }^{34}$ but in the present study with cementoblasts, this combination significantly increased the number of TRAPpositive multinucleated osteoclasts in co-culture.

It is well accepted that mononuclear precursor cells are not direct targets of PTHrP, but express the membranebound signaling receptor RANK that interacts with RANKL produced by osteoblast/stromal cells in response to PTHrP. This indirect action of PTHrP induces the differentiation of osteoclastic precursors into multinucleated osteoclasts. ${ }^{12,32,34}$ Some studies found RANKL mRNA and protein along the ruffled border of mature osteoclasts, and expression correlated with osteoclastic activation and survival. ${ }^{30,31}$ In the present study, RANKL levels in cell lysates were detected in untreated RAW osteoclastic precursor cells but did not appear to promote osteoclast activation since there was no TRAP stain detected in untreated RAW cells. Previous studies reported TRAPpositive cells when pre-osteoclasts were cultured on dentin slices and incubated with RANKL. 27,32,35 These results suggest that RANKL can replace osteoblast/stromal cells in the induction of osteoclastogenesis. In agreement with this, addition of soluble RANKL promoted maximum differentiation of mononuclear precursor cells to TRAP-positive multinucleated osteoclasts even in the absence of cementoblasts. PTHrP alone did not promote osteoclastogenesis of these cells suggesting that cementoblasts are necessary to promote RANKL production in response to PTHrP. On the other hand, the direct effect of soluble RANKL on osteoclastogenesis was diminished by the presence of cementoblasts in co-culture, most likely related to the ability of OPG to inhibit osteoclastogenesis.

Recently, a new member of the leukocyte receptor complex (LRC)-encoded family was identified and found to be expressed exclusively in osteoclasts. ${ }^{36,37}$ Named OSCAR, for osteoclast associated receptor, it is expressed in bone marrow derived osteoclasts, RAW 264.7 derived osteoclasts, and in whole bone. Its putative ligand, OSCAR-L, is expressed primarily in osteoblasts/stromal cells. ${ }^{36}$ Virtually nothing has been reported about the role of PTHrP in the induction of OSCAR. Our study suggests that RANKL can induce differentiation and activation of mononuclear precursor cells into TRAP-positive osteoclasts that express the late differentiation gene OSCAR. Since the co-cultures demonstrated OSCAR gene expression that was not increased with treatments, it is possible that cementoblasts may restrict OSCAR gene expression even with RANKL and PTHrP stimulation.

In conclusion, results from this investigation show for the first time that PTHrP regulates OPG/RANKL levels in cementoblasts in a manner comparable to that reported for other cell types within the oral environment, including follicle cells and osteoblast/stromal cells. In periodontal tissues, maintenance of OPG levels by cementoblasts may be essential to protect the root surface from resorption.

\section{ACKNOWLEDGMENTS}

The authors express their gratitude to Christopher Strayhorn, University of Michigan, Ann Arbor, Michigan, for histologic assistance; Taocong Jin, University of Michigan, for assistance with real-time PCR; Eduardo Katchburian, Federal University of São Paulo, for advice and guidance; and the Center for Craniofacial Regeneration (CCR) at the University of Michigan School of Dentistry. The present study was supported in part by a fellowship grant from the Brazilian government (CNPq) to F. Boabaid and by NIH/NIDCR grants DE09532 to M. Somerman and DE14073 to L.K. McCauley.

\section{REFERENCES}

1. Wise GE, Frazier-Bowers S, D'Souza RN. Cellular, molecular and genetic determinants of tooth eruption. Crit Rev Oral Biol Med 2002;13:323-334.

2. Philbrick WM, Wysolmerski JJ, Galbraith S, et al. Defining the roles of parathyroid hormone-related protein in normal physiology. Physiol Rev 1996;76:127-173.

3. Fiaschi-Taesch NM, Stewart AF. Minireview: Parathyroid hormone-related protein as an intracrine factor - trafficking mechanisms and functional consequences. Endocrinology 2003;144:407-411.

4. Philbrick WM, Dreyer BE, Nakchbandi IA, Karaplis AC. Parathyroid hormone-related protein is required for tooth eruption. Proc Natl Acad Sci (USA) 1998;95:11846-11851.

5. Wise GE, Lumpkin SJ, Huang H, Zhang Q. Osteoprotegerin and osteoclast differentiation factor in tooth eruption. J Dent Res 2000;79:1937-1942.

6. Kitahara Y, Suda N, Kuroda T, Beck F, Hammond VE, Takano Y. Disturbed tooth development in parathyroid hormone-related protein (PTHrP)-gene knockout mice. Bone 2002;30:48-56.

7. Wysolmerski JJ, Cormier S, Philbrick WM, et al. Absence of functional type 1 parathyroid hormone $(\mathrm{PTH}) / \mathrm{PTH}$ related protein receptors in humans is associated with abnormal breast development and tooth impaction. J Clin Endocrinol Metab 2001;86:1788-1794.

8. Schipani E, Lanske B, Hunzelman J, et al. Targeted expression of constitutively active receptors for parathyroid hormone and parathyroid hormone-related peptide delays endochondral bone formation and rescues mice that lack parathyroid hormone-related peptide. Proc Natl Acad Sci (USA) 1997;94:13689-13694.

9. Beck F, Tucci J, Russell A, Senior PV, Ferguson MW. The expression of the gene coding for parathyroid hormonerelated protein (PTHrP) during tooth development in the rat. Cell Tissue Res 1995;280:283-290.

10. Tenorio D, Hughes FJ. An immunohistochemical investigation of the expression of parathyroid hormone receptors in rat cementoblasts. Arch Oral Biol 1996;41: 299-305.

11. Ouyang H, McCauley LK, Berry JE, D'Errico JA, Strayhorn CL, Somerman MJ. Response of immortalized murine cementoblasts/periodontal ligament cells to parathyroid hormone and parathyroid hormone-related protein in vitro. Arch Oral Biol 2000;45:293-303. 
12. Suda T, Takahashi N, Udagawa N, Jimi E, Gillespie MT, Martin TJ. Modulation of osteoclast differentiation and function by new members of tumor necrosis factor receptor and ligand families. Endocr Rev 1999;20:345-357.

13. Wise GE, Huang $H$, Zhang Q, Yao S. Effects of injections of PTHrP on tooth eruption and osteoprotegerin gene expression. Int J Oral Biol 2001;26:81-86.

14. Mekaapiruk K, Suda N, Hammond VE, et al. The influence of parathyroid hormone-related protein PTHrP on tooth germ development and osteoclastogenesis in alveolar bone of PTHrP-knock out and wild-type mice in vitro. Arch Oral Biol 2002;47:665-672.

15. McCauley LK, Nohutcu RM. Mediators of periodontal osseous destruction and remodeling: Principles and implications for diagnosis and therapy. J Periodontol 2002;73: 1377-1391.

16. Kostenuik P, Shalhoub V. Osteoprotegerin: A physiological and pharmacological inhibitor of bone resorption. Curr Pharm Des 2001;7:613-635.

17. Khosla S. Minireview: The OPG/RANKL/RANK system. Endocrinology 2001;142:5050-5055.

18. Karsenty G, Wagner EF. Reaching a genetic and molecular understanding of skeletal development. Deu Cell 2002;2: 389-406.

19. Lee SK, Lorenzo JA. Parathyroid hormone stimulates TRANCE and inhibits osteoprotegerin messenger ribonucleic acid expression in murine bone marrow cultures: Correlation with osteoclast-like cell formation. Endocrinology 1999;140:3553-3561.

20. Faucheux C, Horton MA, Price JS. Nuclear localization of type I parathryoid hormone/parathyroid hormone-related protein receptors in deer antler osteoclasts: Evidence for parathyroid hormone related protein and receptor activator of NFKB-dependent effects on osteoclast formation in regenerating mammalian bone. J Bone Miner Res 2002;17: 455-464.

21. Theill LE, Boyle WJ, Penninger JM. RANK-L and RANK: $\mathrm{T}$ cells, bone loss, and mammalian evolution. Annu Rev Immunol 2002;20:795-823.

22. Hasegawa T, Yoshimura Y, Kikuiri T, et al. Expression of receptor activator of NFKB ligand and osteoprotegerin in culture of human periodontal ligament cells. J Periodontal Res 2002;37:405-411.

23. Rani CCS, Macdougall M. Dental cells express factors that regulate bone resorption. Mol Cell Biol Res Commun 2000;3:145-152.

24. D'Errico JA, Berry JE, Ouyang H, Strayhorn CL, Windle JJ, Somerman MJ. Employing a transgenic animal model to obtain cementoblasts in vitro. J Periodontol 2000;71: 63-72.

25. Chomczynski P, Sacchi N. Single-step method of RNA isolation by acid guanidinium thiocyanate-phenolchloroform extraction. Anal Biochem 1987;162:156-159.

26. Nakchbandi IA, Weir EE, Insogna KL, Philbrick WM, Broadus AE. Parathyroid hormone related protein induces spontaneous osteoclast formation via a paracrine cascade. Proc Natl Acad Sci (USA) 2000;97:7296-7300.

27. Shiotani A, Takami M, Itoh K, Shibasaki Y, Sasaki Y. Regulation of osteoclast differentiation and function by receptor activator of NFkB ligand and osteoprotegerin. Anat Rec 2002;268:137-146.

28. Wada N, Maeda H, Tanabe K, et al. Periodontal ligament cells secrete the factor that inhibits osteoclastic differentiation and function: The factor is osteoprotogerin/osteoclastogenesis inhibitory factor. J Periodontal Res 2001;36: 56-63.
29. Oshiro T, Shiotani A, Shibasaki Y, Sasaki T. Osteoclasts induction in periodontal tissue during experimental movement of incisors in osteoprotegerin-deficient mice. Anat $\operatorname{Rec} 2002 ; 266: 218-225$.

30. Kartsogiannis V, Zhou H, Horwood NJ, et al. Localization of RANKL (receptor activator of NFKB ligand) mRNA and protein in skeletal and extraskeletal tissues. Bone 1999;25: 525-534.

31. Shiotani A, Shibasaki Y, Sasaki T. Localization of receptor activator of $\mathrm{NF \kappa B}$ ligand, RANKL, in periodontal tissues during experimental movement of rat molars. J Electron Microsc 2001;50:365-369.

32. Fuller K, Wong B, Fox S, Choi Y, Chambers TJ. TRANCE is necessary and sufficient for osteoclast-mediated activation of bone resorption in osteoclasts. J Exp Med 1998; 188:997-1001.

33. Itoh $\mathrm{K}$, Udagawa $\mathrm{N}$, Matsuzaki $\mathrm{K}$, et al. Importance of membrane or matrix-associated forms of MCSF and RANKL/ ODF in osteoclastogenesis supported by SaOS-4/3 cells expressing recombinant PTH/PTHrP receptors. J Bone Miner Res 2000;15:1766-1775.

34. Fuller K, Owens JM, Chambers TJ. Induction of osteoclast formation by parathyroid hormone depends on an action on stromal cells. Endocrinology 1998;158:341-350.

35. Jimi E, Akiyama S, Tsurukai T, et al. Osteoclast differentiation factor acts as a multifunctional regulator in murine osteoclast differentiation and function. J Immunol 1999; 163:434-442.

36. Kim N, Takami M, Rho J, Josien R, Choi Y. A novel member of the leukocyte receptor complex regulates osteoclast differentiation. J Exp Med 2002;195:201-209.

37. So H, Rho J, Jeong D, et al. Microphthalmia transcription factor and PU.1 synergistically induce the leukocyte 24 receptor osteoclast-associated receptor gene expression. J Biol Chem 2003;278:24209-24216.

Correspondence: Dr. Laurie K. McCauley, Department of Periodontics/Prevention/Geriatrics, School of Dentistry, University of Michigan, 1011 N. University Ave., Ann Arbor, MI 481091078. Fax: 734/763-5503; e-mail: mccauley@umich.edu.

Accepted for publication January 12, 2004. 